\title{
Paideusis
}

\section{Replies to the Reviews}

\section{Harvey Siegel}

Volume 11, Number 2, 1998

URI: https://id.erudit.org/iderudit/1073103ar

DOI: https://doi.org/10.7202/1073103ar

See table of contents

Publisher(s)

Canadian Philosophy of Education Society

ISSN

0838-4517 (print)

1916-0348 (digital)

Explore this journal

Cite this article

Siegel, H. (1998). Replies to the Reviews. Paideusis, 11(2), 27-37.

https://doi.org/10.7202/1073103ar

(C) Harvey Siegel, 1998

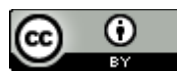

This document is protected by copyright law. Use of the services of Érudit (including reproduction) is subject to its terms and conditions, which can be viewed online.

https://apropos.erudit.org/en/users/policy-on-use/ 


\section{Replies to the Reviews}

\section{Harvey Siegal, University of Miami}

I am grateful to Walter Okshevsky and to Frederick S. Ellett, Jr. and David P. Ericson for their thoughtful and instructive comments on Rationality Redeemed? As is clear from the generally positive tone and substance of their reviews, Okshevsky, Ellett, Ericson and I enjoy a largely shared orientation to philosophical problems concerning rationality; I am gratified by that common orientation. But, of course, there are differences among us on some matters of detail, and on some broader philosophical matters as well. I will try to respond to what I take to be their main concerns.

\section{Reply to Okshevsky}

I am flattered by Okshevsky's generous compliments concerning both earlier writings and the book under review. More importantly, I am in Okshevsky's debt for undertaking to clarify "the kind of project [I am] engaged in." He is right to emphasize my preoccupation with characterizing rationality and with exploring "the irreducibly normative function of [that] regulative ideal governing the operation of principles and criteria of reason assessment." His portrayal of the problem I attempt to address in the book- of showing why my conception of rationality, and my advocacy of it as a fundamental educational and intellectual ideal, need not and should not be thought to be "naively suspended in a time long past and best ignored"-masterfully articulates the challenges facing any friend of Enlightenment conceptions and ideals in today's intellectual climate. His careful account of "The Aim" and "The Method" of my musings clearly articulates both what I am after and how I am trying to get it. He draws connections between my efforts and those of Habermas, Gadamer, and Maclntyre, which are surprising (to me, at least) but welcome. Equally welcome are his clarifications of the ways in which my arguments are or are not transcendental and the sense in which epistemology is in my view autonomous; and his explanations of my emphasis on the distinctions between what is or what is taken to be a good reason for or genuine criterion of reason assessment-which distinctions are required $I$ argue for an account of reasons to be suitably normative-and of the fallible character of all judgments of such goodness.

I am not entirely comfortable with Okshevsky's distinction between criteria and principles of reason assessment. On his view, criteria are first-level constraints on such assessment which are context-sensitive, while principles are meta-level constraints which are not. I view criteria as those considerations which determine quality (in this case, of reasons), and principles as a mixed set of considerations which sometimes serve as alternative articulations of such criteria, sometimes serve to justify the choice of criteria as genuine, and sometimes serve as directives to judgment. For example, in elementary judgments of probability, an important constraint on proper judgment concerns sample size. "Generalize only on the basis of a sample of sufficient size" (or, alternatively, "Don't generalize on the basis of too small a sample") can be readily understood as a principle of reason assessment governing such probability judgments (that is, "Assess probability judgments in part in terms of the adequacy of the 
size of the sample on which such judgments are based). It can equally well be understood as an articulation of one important criterion of good probabilistic judgment-that is, adequate sample size-which enables us to distinguish good judgments from not-so-good ones (and which is itself justified by higher-order considerations gleaned from probability theory). It can also be understood, readily enough, simply as a directive to judgment. In any case, my preference and my practice is in most cases to use the terms "criteria" and "principles" more or less interchangeably, and to distinguish putative from genuine, and context-specific from context-independent, principles/criteria as appropriate. But Okshevsky is entirely right to stress the distinction between first-order and meta-level constraints on reason assessment, and I find compelling and clarifying his analysis of the ways contextual matters relate to each. As he makes clear, some of the demands of reason are "universal" and context-independent (for example, a good reason in any context cannot be arbitrary or internally inconsistent), while some features of reasons and their proper assessment are "local" and context-specific (for example, a good reason in most branches of mathematics must be "formal"; a good reason for a person's choosing a particular lifestyle or career must take into account the values, interests, and proclivities of that person, as well as the characteristics of the society of which she is a part). Leaving aside the essentially verbal matter of whether to label first-order constraints "criteria" and meta-level constraints "principles," I am in Okshevsky's debt for his explanation of the way the first-order/meta- distinction functions in my position, for his clarification and defense of the secondorder universalistic dimensions of that position, and for his persuasive explanation of the ways in which my less-than-perspicuous claims on this matter have been subject to misinterpretation. He has explained and defended these aspects of my view, and my "minimalist transcendental project" more generally and more ably than I have been able to do myself.

I confess that, on occasion, Okshevsky puts his points in ways that I do not find completely clear. My sense is that Okshevsky's familiarity with the hermeneutical tradition enables him to articulate claims and arguments in such a way that philosophers steeped in that tradition (which I, for better or worse, am not) can readily appreciate them. This is an extremely valuable talent. Indeed, Okshevsky's obvious familiarity and comfort with both analytic and Continental traditions makes him ideally suited to bridge the gulf which divides these traditions and to enable dialogue across the differences between them. I applaud this, and thank Okshevsky for "translating" my work into the language of this other discourse.

\section{Reply to Ellett and Ericson}

I am indebted to Ellett and Ericson for their wide-ranging and generally sympathetic discussion. I am particularly grateful to them for their kind remarks concerning my ham-fisted attempts to engage "newer philosophical voices; and for their resolute insistence that, even if my response to it is problematic, I at least have a "firm, intuitive sense of the fundamental philosophical issue at stake."

Ellett and Ericson characterize my "critical thinker" (and William Hare's "open-minded person"), in contrast to Hirst's "liberally-educated person," as a "super-liberally educated person"-_"super" because, according to Hirst, the 
liberally-educated person has 'merely 'sufficient immersion' in the concepts, logic, and criteria of the disciplines"; on my view, the critical thinker has "encyclopaedic knowledge ... a specialist knowledge of one trained in all the details ... and a technician's knowledge of detailed application, as well as Hirst's disciplinary understanding and also a complex set of dispositions, habits of mind, and character traits. The contrast is apt and Ellett and Ericson are right that my conception is more demanding than Hirst's. But it should be pointed out that this is, at least, partly explained by noting that I have attempted to characterize an ideal-which, in the nature of things, is such that ordinary mortals will not fully achieve it-while Hirst has not. While many-indeed, most-people are critical thinkers to some degree or other, and no person is an ideal critical thinker. The educational task of fostering critical thinking is, thus, always open for everyone. Hirst, by contrast, would, I think, be happy to declare that many people have fully achieved the status of liberally-educated person, in that they have the requisite immersion, disciplinary-based understanding, and critical appreciation. This may I hope go some way towards dispelling Ellett and Ericson's implicit suggestion that my view of critical thinking is too demanding. That said, though, I do think it important that educational aims and ideals extend beyond disciplinary concerns, and in several directions; Ellett and Ericson are right to draw this contrast between Hirst's views and my
own.

Ellett and Ericson complain that my view does not allow sufficient scope for "legitimate trust and respect for the legitimate intellectual authority of others." They are right to insist on due recognition of legitimate trust and respect for legitimate intellectual authority. It is not true, however, that my view does not acknowledge the point. Indeed, they cite other work of mine which "stress[es] the institutional (collective) aspects of rationality"; they might also have cited my "Rationality and Epistemic Dependence" (1988a) which addresses the topic at some length. On the substantive point, in any case, we are agreed: rationality must be understood not only at the individual level, but socially/institutionally as well; and at the individual level, room must be made for the rational propriety of legitimate trust in and respect for the legitimate intellectual authority of others. My only addition here is that determining when trust and the intellectual authority of others are indeed legitimate is a matter falling clearly under the ambit of critical thinking: it is up to individuals to determine when, in matters epistemic, to trust the judgments or respect the intellectual authority of others; such determinations, if well executed, will be appropriately guided by reasons.

Ellett and Ericson pay my epistemological musings some high compliments; for them, I am grateful. I am pleased, too, by the fact that in the end our positions seem quite close; they make several connected criticisms of my discussions of various matters philosophical, but these seem to me to be partly terminological and partly of secondary importance overall. In any case, I address what I take to be their most important criticisms next.

\section{Naturalism}

As I understand them, one of Ellett and Ericson's main worries is that my view is insufficiently "naturalistic," and, relatedly, too accepting of "necessity." I address these complaints in this and the following two sections. 
Ellett and Ericson have a lot to say about naturalism; with much of it, I agree. They are right to insist that Kant and Quine are not the only options with respect to what they call "Iegitimation"; that Quine's naturalism is neither the only form of naturalism available, nor the most compelling of the available versions of it; that the vast majority of interesting truths which inquiry reveals are not necessary truths; that there is no necessary framework governing inquiry; and that there is no "FIRST" philosophy as they define it. But I find some of their claims here uncompelling. They align themselves with "the 'naturalists' who argue that the strong Kantian program fails, but their characterization of that rejected program is rather quick. If it is characterized very strongly, such that the only truths are $a$ priori, necessary or transcendental truths-as Ellett and Ericson seem to suggest-I would reject it, too. But as I understand the term, naturalists with respect to epistemology hold that all legitimate epistemological questions, including those concerning the character of legitimation or justification, are answerable by appeal only to natural (including social) science. I have argued against this view in a variety of ways and in a variety of places. ${ }^{1}$ In any case, whether or not there is a serious disagreement between Ellett and Ericson and me on naturalism depends on a much more precise characterization of both that doctrine and the relevant arguments for and against it. As far as I can tell, there is not too much substantive disagreement between us: I, too, reject overly strong forms of "Kantian transcendentalism"; they, too, as far as I can tell, reject the reduction of epistemology to empirical science and hold open the possibility of philosophical justification of philosophical positions. (After all, in their review they seek to establish many philosophical points, none of which are defended by appeal to natural science.) I, too, reject their sense of "FIRST" philosophy, according to which "[p]hilosophy must start from necessary principles or constraints; but I accept, and they may too, the weaker sense of "first philosophy" which Quine rejects, according to which philosophy can legitimately pose the question of the epistemic status of science, and answer it without question-beggingly assuming the legitimacy of the very science whose status is at issue (Siegel 1995, 1996). Ellett and Ericson are apparently concerned to establish that for naturalists, "knowledge also has to be reconceived so that it yields provisional solutions rather than necessary truths. The suggestion here seems to be that non-naturalists conceive all genuine knowledge as knowledge of necessary truths, but this is false; the provisional, fallible nature of at least empirical knowledge is readily granted by non-naturalists. They are also apparently concerned to establish that for naturalists "it is . . . impossible to achieve a Godlike necessary framework for all inquiry." Which contemporary non-naturalist holds that there is any such necessary framework? Not me! (See Siegel (1987), ch. 2) In their zeal to reject all sorts of necessity on naturalism's behalf, Ellett and Ericson mischaracterize their non-naturalist opponents. At least, they mischaracterize me if they suppose that I hold these things. In their sense of "naturalism"-no first philosophy, no infallible knowledge, no necessary framework for all inquiry-I'm happy to sail under that banner, too! So again, despite appearances, we seem on substantive matters to be largely in agreement. I hope so. In any case, I look forward to further clarification of the actual status of these possible disputes between us in the future. 


\section{Truth and Justification}

I find Ellett and Ericson's discussion of truth confusing. They claim that I claim that the law of excluded middle (for all $p$, either $p$ or not-p) is a necessary truth. But on the page they cite I make no such claim. For the record, I do not regard it as a necessary truth, if that is taken to mean or entail (as they take it) that multi-valued logics are (necessarily) logically incoherent. But their conception of such logics is, to say the least, non-standard. The idea underlying multi-valued logics is that there can be truth values other than "True" and "False" (that is, "Indeterminate"). But Ellett and Ericson take multi-valued logics to be those which admit a plurality of plausible theories, and an openness to the possibility that in any domain there might be no uniquely plausible theory. But "plausible" is not a truth value-when I judge that theory $\mathrm{T}$ is plausible, I am not attributing to it a truth value at all; $a$ fortiori I am not attributing to it a truth value other than "True" or "False." The judgment that $T$ is plausible is rather a judgment concerning T's epistemic status. Ellett and Ericson's discussion here, I fear, confuses truth and justification. A person who holds strictly to the law of excluded middle-whether or not she regards that law as a necessary truth-can cheerfully concede a plurality of equally plausible alternatives in a given domain of inquiry at a given time. Since their discussion occurs in the context of a consideration of my conception of truth as absolute, let me state for the record that that conception acknowledges fully that in any given domain there can be alternative, equally plausible theories: the existence of one absolute truth on a particular topic in a particular domain-for example, concerning the causal etiology of a given instance of lung cancer-is perfectly compatible with the existence at a time of a plurality of equally plausible, equally justified hypotheses concerning that causal etiology. In any case, as above, we appear to be in agreement on the substantive issue; there need not be a uniquely plausible theory in any domain of inquiry ${ }^{2}$.

\section{Necessary, Analytic, A Priori, Logical, Certain, and Conceptual Truth}

In their zeal to embrace the " 'naturalistic' spirit," Ellett and Ericson "reject reliance on the modalities, whether logical, natural, or linguistic, as fundamentally unclear. Necessity in all its guises is thus abjured and the notion of analyticity as well." Their discussion suggests that they consider a prioricity, analyticity, logicality, certainty, and conceptuality (if I may put it that way) to be forms or "guises" of necessity; and they reject them all.

This is too quick for these things are not equivalent. Goldman, perhaps the preeminent naturalistic epistemologist writing today, instructively distinguishes these various alleged sorts of necessity, and shows that the naturalist can perfectly well acknowledge that some truths (that is, the truths of logic) are necessary or a priori without compromising her naturalism (Goldman (1986), 48-9, 299 ff.). Kripke (1972) has famously distinguished between necessity and a prioricity, showing that particular truths-for example, that concerning the atomic number of gold-are a posteriori but nevertheless necessary. Many other authors and works could be cited, but the point is $I$ hope clear: Ellett and Ericson move too quickly in equating and rejecting all these alleged "guises of necessity" in one stroke. 
Perhaps the most interesting example of this is their rejection, allegedly on the basis of arguments of van Fraassen, of conceptual truth. In response to my claim that "claims which are rationally justified are claims which we have reason to regard as true," Ellett and Ericson write:

Siegel says this is a conceptual truth. But the work of van Fraassen (1980) shows this is not a conceptual truth. Scientists can have good reasons for accepting a theory (because it explains the phenomena) and yet not take the theory to be true.

This misrepresents van Fraassen's position. First, van Fraassen denies that explanatory ability constitutes a reason for acceptance; he argues strenuously against any such inference to the best explanation. More importantly for present purposes, van Fraassen's "constructive empiricism" holds that the evidence permits scientists to regard a well-confirmed theory as "empirically adequate," and to regard the observational claims of the theory as true, but not to regard the theoretical claims of the theory as true. (van Fraassen requires and defends a sharp theory/observation distinction, which I suspect Ellett and Ericson would find problematic, but let that pass.) This is because, on van Fraassen's view, the evidence is never such that it provides good reasons to believe the theoretical claims of the theory, or that the theoretical entities the theory posits actually exist. On his view, evidence can provide good reasons for believing observational claims, but not for believing theoretical claims. In parallel fashion, van Fraassen holds that evidence can justify scientists' belief in the truth of observational claims, but not theoretical ones. In other words, on van Fraassen's view, as on mine, if a scientist has good reason to believe that $p$, she has good reason to believe that $p$ is true. Van Fraassen claims just that while the evidence may provide good reason to believe a theory's observational claims, it never provides good reason to believe a theory's theoretical claims; and, consequently, that while a scientist can have good reason to believe a theory's observational claims, she can never have good reason to believe its theoretical ones. But when a scientist has good reason to believe that $p$ (for either observational or theoretical $p$ ), she has good reason to believe that $p$ is true. The "conceptual truth" in question is fully respected by van Fraassen's view.

I conjecture that Ellett and Ericson err here because they collapse van Fraassen's distinction between belief and acceptance. They use the latter term in their charge against me, while my claim (in the same paragraph from which Ellett and Ericson quote) utilizes the former- "to believe that $q$ just is to believe that $q$ is true." For van Fraassen, the distinction is of paramount importance, precisely because "acceptance," as he uses it, does not have the implications concerning truth which "belief" has: to accept a theory is one thing; to believe it, quite another. Once this distinction's role in van Fraassen's view is recognized, Ellett and Ericson's attempt to use van Fraassen in arguing against the allegedly "conceptual" truth in question collapses (van Fraassen (1980), pp. 12, 16-19, 46-47, passim; also, van Fraassen (1985), 276-281).

In the end, I am not sure how much turns on this matter. It is true, uncontroversially, I think, that to believe that $p$ just is to believe that $p$ is true. After all, to deny it-for example, to declare it unproblematic to assert "I believe that Ellett and Ericson are great philosophers, but I do not believe that it is true that they are"-is, if not straightforwardly to contradict oneself, to 
embroil oneself in difficulties which are notoriously difficult to overcome. (If the second clause in the example is accepted, how is the first clause even to be understood? What does "belief" in the first clause come to?) So, I continue to maintain that to believe that $p$ just is to believe that $p$ is true (and, by implication, that to regard a claim as rationally justified is to regard oneself as having reason for thinking it true). Is this a conceptual truth? I see no harm in calling it so, although I do not call it that on the page which Ellett and Ericson cite-but I am happy to call it something else if readers find "conceptual truth" problematic due to associations that locution has accrued during the history of philosophical discussion. I readily grant that concepts and meanings change over time and differ across historical/cultural locations (and are often vague, ambiguous, and/or imprecise in any case), so calling it a conceptual truth does not make it a necessary truth in the sense that it is certain, can never be given up, or is true even when the terms are understood to have different meanings. (Since such truths are not certain, allowing them is consistent with global fallibilism.) For those enamored of Quine's critique of analyticity, I am happy to qualify the locution still further, and say that "conceptual truths" such as the one on the table are largely but perhaps not wholly true in virtue of the meanings of the relevant terms, thereby making room for Quinean holism. Still, whatever one's theory of meaning, conducting philosophy's business does require close attention to concepts and meanings, and, given the meanings (currently, in the historical-cultural location that Ellett, Ericson, and I share) of the relevant terms "reasons," "justification," "truth," and especially "belief," it does seem to me exceedingly difficult to deny that having reasons which justify belief that $p$ is tantamount to having reasons which justify belief that $p$ is true. That is part of what belief is. Perhaps I am being hasty here. Can Ellett and Ericson supply a counter-example-that is, a (real or imagined) case of genuine belief (not acceptance) that $p$ in which the believer does not believe that $p$ is true?

\section{Universality}

Ellett and Ericson criticize my discussion of universality. Taking the concept of probability as their example, they write: "Siegel suggests that a concept/criterion is universal because it is binding on all rational inquirers. But how can Siegel know that the concept of "probability" is universal? How can he show that the concept we use today will be the same one that all our rational ancestors [sic] will be using?" There are two cases here: concepts and criteria. I take them in turn.

The first case is quickly dispatched. Nowhere do I suggest, nor do I believe, that concepts are universal. Ellett and Ericson are right that concepts (such as the concept of probability) are invented at, and utilized in, particular historical/cultural locations; that they evolve, develop and go in and out of use over time, and so on. On this, we are agreed. I can only wonder why Ellett and Ericson think that I think otherwise.

The second case is trickier. Are criteria universal? Are they binding on all rational inquirers? Some criteria, I believe, are. Consider the example mentioned earlier: for a probabilistic generalization to be reasonable, it must not be based on too small a sample. This criterion is universal in the sense that any probability judgment which fails to honor it is defective; it is in this sense "binding on all rational inquirers." Of course, some inquirers will not be aware 
that this criterion "binds" their probabilistic judgments; whether or not that ignorance calls into question their status as "rational" inquirers depends on a further filling out of the case. (We would not ordinarily fault an inquirer whose judgments failed to honor the criterion if, for example, she lived before the invention of the concept or theory of probability; we would fault an inquirer who so judged after completing her first statistics course.) Whether or not such failures are culpable, it nevertheless remains that judgments which fail to honor the criterion are insofar defective. In this sense, the criterion is universal.

But what if our beliefs concerning probability change? What if, at some time in the future, we no longer regard the criterion as legitimate? What if, more broadly, we give up our allegiance to the range of criteria expressed by the general norm "Good probabilistic reasoning is reasoning which accords with the probability calculus"? Here, I happily agree with Ellett and Ericson that the future course of inquiry may be such that we give up our commitment to that calculus. If we do, we will no longer regard the associated criteria governing probabilistic judgment as legitimate. But insofar as we continue to so regard them, they will be universal in that they apply to the evaluation of all such judgments (independently of the epistemic blameworthiness of those whose probabilistic judgments fail to honor them). So the universality of such criteria is compatible with future changes in our estimation of them as inquiry proceeds. $^{3}$

\section{Ontology}

According to Ellett and Ericson, "[t]he major problem [with my view] is that Siegel never successfully links rationality (or epistemology) to any ontological position." It is true that I have not addressed metaphysical issues very often or in much depth. Why this is a problem for my view of rationality or epistemology, though, let alone "the major problem" with it, is unclear. Ellett and Ericson favor what they call "minimal realism"; it will come as no surprise that I, too, favor a moderate form of realism, as my various remarks on absolute truth might suggest. So here, too, on substantive matters Ellett and Ericson and I are in agreement. I repeat, though, that it is completely unclear why my alleged failure to link rationality and ontology somehow constitutes a major problem for the epistemological view I lay out. (Their only suggestions are (i) that I face some problem concerning reference, of which I confess I cannot make sense; and (ii) that "[1]inking rationality and a 'minimal realism' will also help to provide a viable answer to certain kinds of skeptic who ask 'Why should I be rational?' by showing how one's ends can be achieved." Two brief comments in reply: first, I have answered this skeptic in chapter 5 of the book under review; Ellett and Ericson offer no reason to think that this answer fails. Second, their own answer rests on regarding rationality as wholly instrumental; I have argued against such a construal of rationality in several of my works (1996a, 1996b, 1997, and 1998).)

I should note that Ellett and Ericson's defense of realism fails by their own lights. They begin by agreeing with Putnam (in his "internal realism" phase) that the view that Putnam had advanced in an earlier period (his "metaphysical realism" phase) fails. The "failed" earlier view rested on arguments based on the approximate reference of theoretical terms, and on the famous "miracle argument"-if theoretical terms in mature theories do not at 
least approximately refer, and if those theories do not get the world at least approximately right, the success of science would be a miracle. Agreeing with the later Putnam that these defenses of realism fail, Ellett and Ericson say that

... [i]f realism is to be defended, it will have to be in a more 'indirect,' holistic manner. The first step starts from the fact that the technologies related to modern physical science are causally powerful and effective. One, then, reasonably infers from this that modern science is somehow in touch with reality.

This, alas, is the very miracle argument that the earlier Putnam posed and the later Putnam rejected: if science is not "somehow in touch with reality," the causal power and effectiveness of "the technologies related to modern (physical) science" would be miraculous. Ellett and Ericson claim to be following the later Putnam here. I do not think they can be if their defense of realism rests on the very argument for realism that that Putnam rejects.

In any case, on the substantive issue we are, again, agreed: Ellett and Ericson and I both accept a (not too strong) version of realism. It remains to be shown that my various epistemological claims require either this ontology, or any ontology, for their defensibility. Why, exactly, is my relative neglect of ontology a major problem for my epistemological views? I would welcome clarification of this point from Ellett and Ericson.

\section{Kant and Morality}

Ellett and Ericson claim that my "Kantian line of argumentation has grave difficulties," but do not actually say which line of argumentation they have in mind. There are four possibilities they mention: (a) my claim that the ideal of critical thinking is justified by appeal to the Kantian notion of respect for persons, (b) a general but unspecified "Kantian approach to ethics," (c) Kant's "general strategy" of "employing reason in order to discover transcendentally necessary constraints binding upon itself," and (d) using Kant to argue for particular "political/social principles in a pluralistic society." A word about each:

(a) While Kant emphasized the idea, that persons qua persons are deserving of respect is agreed by most moral theories. For example, standard forms of consequentialism and virtue ethics also accept it (though it plays a less central role in those theories). It is, I think, uncontroversial within ethical theory that persons qua persons are deserving of respect. (Ellett and Ericson do not challenge it.) Of course, the tricky thing is to establish what respectful treatment requires. Here, my claim, following Scheffler, is that the respectful treatment of students requires explicit and sustained effort to foster their rational skills and dispositions, and by doing so both to empower them and to acknowledge, strengthen and celebrate their independence and autonomy. This is my main use of Kant with respect to moral matters. As far as I can see, nothing in Ellett and Ericson's review challenges this claim.

(b) Ellett and Ericson dismiss "any Kantian approach to ethics" in a sentence which appeals to the authority of seven well-known critics of Kant. While I acknowledge the relevance of the work of those critics, the bare appeal to their work settles nothing. Moreover, two can play this game: well-known and highly respected philosophers such as Onora O'Neill, Christine Korsgaard, 
Barbara Herman, and Marcia Baron have provided important defenses and developments of the "Kantian approach." Leaving this battle of authorities to one side, the key point here is that my justification of critical thinking as an educational ideal does not rest on some general "Kantian approach to ethics," but only on the principle of respect for persons, which is acknowledged by more or less all the major approaches to ethical theory. Consequently, even if Ellett and Ericson are right that that approach is deeply problematic, whatever problems it faces are problems for the approach, not for my proffered justification of that ideal.

(c) Ellett and Ericson are right that I do avail myself of a version of what they call "Kant's general strategy"- that is, I offer "transcendental" arguments at various points in my discussion, especially in chapter 5 and the Epilogue where I am addressing the questions "Why be rational?" and "Why care about rationality?" Ellett and Ericson reject this strategy, both on the authority of Albert and Margolis and on the basis of their earlier discussion of necessity. As argued above, though, that discussion of necessity is in several ways problematic. I regret that Ellett and Ericson restricted themselves to brief discussion of that general strategy, rather than offering any criticisms of my actual transcendental arguments. I believe that the rather weak form of transcendental argument I utilize-which, as I argue in the book, is completely in keeping with my commitment to fallibilism-avoids the difficulties often attributed to Kant. But only attention to the actual arguments will allow us to discern whether Ellett and Ericson's critique of the general strategy establishes the untenability of those arguments. I do not think that it does. 4

(d) I quite agree with Ellett and Ericson that a simple appeal to Kant is insufficient to resolve outstanding controversies - that is, that between liberalism and communitarianism in social and political philosophy. Here, I think it sufficient simply to note that I never said or thought otherwise.

\section{Conclusion}

It is ironic that I have devoted most of my remarks to criticisms of Ellett and Ericson, because $I$ think that in the end our respective views will turn out to be quite close. I hope my (perhaps overly "picky") reply to them will be taken by readers as attempts at clarification and a search for common ground, rather than just another instance of "male" philosophical aggression. In any case, I close simply by thanking them for their wide-ranging discussion, which no doubt will result in long, enjoyable conversation, with appropriate libation, at the next Philosophy of Education Society meeting-first drink's on me! It is my pleasure to thank Okshevsky as well, for his insightful and highly sympathetic reading of my book. (Two drinks for Walter!) I am a fortunate author indeed to have my book taken so seriously by three such well-read and acute philosophers. Thanks, finally, to John Portelli, editor of this journal, for the invitation to participate in this conversation.

\section{Notes}

${ }^{1}$ See, most recently, my (1995), (1996), (1996a), and (1996b). Since Ellett and Ericson claim to follow Hooker, of particular note is my exchange with Hooker: my (1997) and (1998), sandwiching Hooker's (1998). 
2Two asides: (i) Ellet and Ericson suggest that because I accept Peirce's fallibilism, I accept his definition of truth in terms of the ultimate results of inquiry. I do not; (ii) Contrary to their suggestion, irrational numbers, parallel lines meeting, wave/particle duality, and so on are not violations of the law of excluded middle.

${ }^{3}$ See Siegel(1998), 133-5, for an earlier articulation of this point. Thanks to Fred Ellet, who helped me to understand his and Ericson's basic worry here. I hope these remarks serve to quiet their doubts. I strongly recommend Okshevsky's discussion of universality in this issue of Paideusis.

${ }^{4}$ Here again, I recommend Okshevsky's depiction of my "minimalist" transcendental project.

\section{References}

Goldman, A. (1986). Epistemology and Cognition. Cambridge, MA: Harvard University Press.

Hooker, C. A. (1998). "Naturalistic Normativity: Siegel's Scepticism Scuppered." Studies in History and Philosophy of Science, 29 (in press).

Kripke, S. (1972). "A Naming and Necessity." In D. Davidson and G. Harman, eds., Semantics of Natural Language (Second edition). Dordrecht: D. Reidel, 253-355 and 763-769.

Siegel, H. (1987). Relativism Refuted: A Critique of Contemporary Epistemological Relativism. Dordrecht: D. Reidel.

Siegel, H. (1988). Educating Reason: Rationality, Critical Thinking and Education. New York: Routledge.

Siegel, H. (1988a). "Rationality and Epistemic Dependence." Educational Philosophy and Theory, 20(1), 1-6.

Siegel, H. (1995). "Naturalized Epistemology and First Philosophy." Metaphilosophy, 26(1), 46-62.

Siegel, H. (1996). "Naturalism and the Abandonment of Normativity." In W. O'Donohue and R. Kitchener, eds., The Philosophy of Psychology. London: Sage, 4-18.

Siegel, H. (1996a). "'Instrumental Rationality and Naturalized Philosophy of Science." Philosophy of Science, 63(3), Supplement (PSA Proceedings, Part 1), S116-124.

Siegel, H. (1996b). "Naturalism, Instrumental Rationality, and the Normativity of Epistemology." Proto Sociology, 8/9, 97-110.

Siegel, H. (1997). "Hooker's Revolutionary Regulatory Realism." Studies in History and Philosophy of Science, 28 (in press).

Siegel, H. (1998). "Naturalism and Normativity: Hooker's Ragged Reconciliation." Studies in History and Philosophy of Science, 29 (in press).

van Fraassen, B.C. (1980). The Scientific Image. Oxford: Clarendon Press. van Fraassen, B.C. (1985). "Empiricism in the Philosophy of Science." In P.M. Churchland and C.A. Hooker, eds., Images of Science: Essays on Realism and Empiricism. University of Chicago Press, 245-308. 